\title{
STUDY ON THE DISTRIBUTION OF GEOLOGICAL HAZARDS BASED ON FRACTAL CHARACTERISTICS - A CASE STUDY OF DACHUAN DISTRICT
}

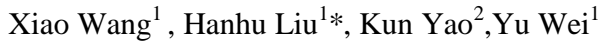 \\ ${ }^{1}$ College of Earth Sciences ,Chengdu University of Technology, Chengdu, Sichuan,the People's Republic of \\ China,wxcdlg0322@163.com \\ ${ }^{2}$ College of resources and environment, Xichang University, Xichang,Sichuan, jiangshan996@126.com
}

Commission III, ICWG III/Iva

\begin{abstract}
KEY WORDS: Geologic Hazard, Fractal Theory, Fractal Dimension, Self Correlation, Risk Zoning
\end{abstract}
\begin{abstract}
:
It is a complicated process to analyze the cause of geological hazard. Through the analysis function of GIS software, 250 landslides were randomly selected from 395 landslide hazards in the study area, superimposed with the types of landforms, annual rainfall and vegetation coverage respectively. It used box dimension method of fractal dimension theory to study the fractal characteristics of spatial distribution of landslide disasters in Dachuan district, and analyse the statistical results. Research findings showed that the The fractal dimension of the landslides in the Dachuan area is 0.9114 , the correlation coefficient is 0.9627 , and it has high autocorrelation. Zoning statistics according to various natural factors, the fractal dimension between landslide hazard points and deep hill, middle hill area is strong as well as the area whose average annual rainfall is $1050 \mathrm{~mm}-1250 \mathrm{~mm}$ and vegetation coverage is $30 \%-60 \%$. Superposition of the potential hazard distribution map of single influence factors to get the potential hazard zoning of landslides in the area. Verifying the potential hazard zoning map of the potential landslides with 145 remaining disaster points, among them, there are 74 landslide hazard points in high risk area, accounting for $51.03 \%$ of the total. There are 59 landslides in the middle risk area, accounting for $40.69 \%$ of the total, and 12 in the low risk area, accounting for $8.28 \%$ of the total. The matching degree of the verifying result and the potential hazard zoning is high. Therefore, the fractal dimension value divided the degree of geological disaster susceptibility can be described the influence degree of each influence factor to geological disaster point more intuitively, it also can divide potential disaster risk areas and provide visual data support for effective management of geological disasters.
\end{abstract}

\section{INTRODUCTION}

China is a country with frequent geological disasters. With the rapid development of national economy, the construction of human activities and basic projects is constantly expanding, the worsening progress of the geological environment and the frequency of geological disasters have gradually increased (Du, 2017). Sichuan province has a special geological structure, it has obvious 2 points, the southeast is the platform area and the northwest is the geosyncline area. The topography of the east and west of Sichuan is very different and the geomorphology is complex. Because of it, Sichuan province has become the province with the largest number of geological disasters, the most complete types, the highest frequency, the largest scale and the hardest-hit places in the whole country (Yan and Yue, 2004). After the "5.12" Wenchuan Earthquake in 2008, the central and provincial authorities have stepped up their efforts in preventing geological hazards (Luo, 2014). However, the geological factors and external forces are constantly changing, and the prevention and control of geological disasters should also be strengthened and put forward to the corresponding measures. Therefore, it is important to carry out monitoring and control of comprehensive geological hazards and hidden dangers. Studying the fractal relationship between natural factors and disaster points is of great practical value for disaster early warning and control.

Scholars at home and abroad have explored many good results in the assessment and prevention of geological disasters. Based on the probability and statistics method, the evaluation method of county vulnerability and its classification standards are discussed(Li et al., 2017); The complex relationship between urbanization and geological disasters is explored by using the coupling coordination degree classification method (Han and Zhang., 2017); Using high score data to construct 3D visualization platform to interpret geological disasters (Zhang and Zhuang, 2017); Scholars have developed landform landslides in order to assess vulnerability to shallow landslides (Zieher et al., 2016); Comprehensive assessment of the source area in the process of slope instability caused by earthquake induced landslides (Caccavale et al., 2017); A simplified analysis method of shallow landslides based on physical model is verified and the performance of slip as an early warning tool is evaluated (Schilirò et al., 2016). In this paper, the fractal theory is adopted to explore the linear relationship between the single element and the distribution of geological disasters. It is able to obtain the factors that have a significant impact on the distribution of disasters and at the same time divide the schematic diagram of potential disaster risk zoning to provide a

\footnotetext{
* Hanhu Liu -23598298@qq.com
} 
theoretical basis for the decision-making departments to adopt reasonable and effective governance methods.

\section{STUDY AREA SURVEY AND DATA SOURCES}

\subsection{Research area survey}

Dachuan District is located in the northeast of Sichuan Province, which belongs to the typical area of soil erosion control in the middle and lower reaches of the Jialing River (Luo et al., 2017). It is transportation hub in Northeastern Sichuan basin and the important material and distribution center of Sichuan and Chongqing, with an area of 2245 square kilometers. The study area is high in the north and low in the southeast. It belongs to the subtropical monsoon humid climate, with a mild climate, a plenty of heat, four distinctive seasons. Spring comes earlier here, the summer lasts longer, and the fall winter time continues to be moderate. There are plenty of precipitation in this area, but the distribution is uneven, the summer is much dry, and the autumn and winter are cloudy and rainy. There are plenty of precipitation in this area, but the distribution is uneven, the summer is much dry, and the autumn and winter are cloudy and rainy. There are frequent disastrous weather in agriculture and obvious stereoscopic climate in mountain areas. At the same time, it is rich in coal, iron, rock salt, oil and other mineral deposits (Office of the People's Government of Dachuan District in Dazhou City, 2017). The terrain of this area is complex and diverse, the cutting density is large and the frequency of the rainstorm is very high, which belongs to the geological disaster area of our country.

\subsection{Data source}

This article mainly uses the following data: (1) Administrative division map of Dachuan District; (2) The geological map of 1:5 million and the map of rock and soil in Sichuan province; (3) Monthly rainfall data of the meteorological stations in the Dachuan District and the surrounding meteorological stations in 2013; (4) Data of field survey in the whole region of Dachuan District in 2013-2017 years. There are 395 landslides, including 3 large landslides, 8 large landslides, 20 medium-sized landslides and 364 small landslides. (5) NDVI data with spatial resolution of 250 meters in Dachuan area in 2013.

\section{AN OVERVIEW OF FRACTAL THEORY}

\subsection{Basic concepts}

Fractal theory is a kind of nonlinear scientific theory. The theory described the complex disorder and scale invariant system based on the self-similarity of a certain substance, and explored the fine structure inside the chaos. Therefore, its theory and method have been widely used in various disciplines and their branches (Burrough, 1981; Zhang et al., 2017).

The fractal theory was proposed by American scientist Ben Hua Mandbo in 1967.This theory aimed to explore the seemingly unpredictable and irregular phenomena in nature, and to find the self-similarity between them, which might be approximate self-similarity or self-similarity in statistical significance. In 1975, he founded the fractal geometry. On this basis, the science of fractal properties and its application is formed, which is called fractal theory (Yang et al., 2017).

\subsection{Fractal dimension}

Fractal dimension, is also known as fractal dimension or fractal dimension. The fractal dimension is based on fractal theory. Because of the self - similarity of the graphics, the fractal dimension was produced. In Euclidean space, people are used to define points as zero dimension, define straight lines or curves as two dimensions, regard plane or sphere as two dimensions, and regard space as three-dimensional. When Einstein introduced the dimension of time, there appeared four dimensions again. If you want to study a problem in a number of ways, you can also build a high dimensional space. This article uses similar dimensions to study.

Similar dimension is one of the most applied fractal dimensions. For a self-similar research object, if it can be divided into $\mathrm{N}$ units ( $\mathrm{N}$ varies with similar ratio $\mathrm{r}$ ), and each unit is similar to $\mathrm{R}$ in terms of similarity ratio, it is defined as:

$$
D S=-\frac{\ln N(r)}{\ln r}
$$

The above definition of fractal dimension is very rigorous in mathematics. But in actual problems and experimental measurements, the length is bounded. In general, this relationship exists if $N(r)$ changes with $r: N(r)-r^{-D}$, then $D$ is the fractal dimension of the graph (Ding, 2012).

\subsection{Determination of fractal dimension}

The fractal dimension reflects the effectiveness of the space occupied by the complex figure, which is a measure of the irregularity of the complex figure. At present, we have known a variety of methods for determining fractal dimensions, such as: (1) we can change the observation scale to find the fractal dimension, (2) we calculate the fractal dimension according to the measure relationship, (3) we use the relevant function to find the fractal dimension, (4) we take the distribution function to find the fractal dimension, etc. This paper mainly studies the fractal characteristics of landslide geological hazards in Dachuan District. The specific process of the method is to plot the landslide on the appropriate administrative division map, cover the administrative area with a small box with an edge length of $r$, and count the number of grids entered by the point or line, which is denoted as N(r) (Wen, 2013); then the box size $r$ is reduced according to the ratio of $1 / 2$, and the corresponding number $\mathrm{N}(\mathrm{r})$ is counted, and so on. The two kinds of values are successively drawn in a double logarithmic coordinate system. Finally, the corresponding double logarithmic curve is fitted by the least squares method.

\section{THE APPLICATION OF FRACTAL THEORY IN DACHUAN DISTRICT}

\subsection{Geological Environment in Dachuan District}

Dachuan is located in the southern margin of the Daba Mountains fold margin depression. In the study area, the fracture, folds are developed and the activity is strong, and the development of the joints and fissures is more developed.

The title should appear centered in bold capital letters, at the top of the first page of the paper with a size of twelve (12) points and single-spacing. After one blank line, type the author(s) name(s), affiliation and mailing address (including e-mail) in upper and lower case letters, centred under the title. In the case of multi-authorship, group them by firm or organization as 
shown in the title of these Guidelines. The main strata in this area are Triassic, Jurassic and Quaternary. The lithology in this area is sandstone, mudstone, sandy mudstone, argillaceous sandstone and siltstone, most of which are soft rock or soft rock The land is seriously weathered and denuded. The loose deposits produced by erosion and erosion provide a rich source of material for the development of landslides. The geomorphological features of Dachuan District are entirely controlled by geological structure and lithology. Since 2005, floods and floods have occurred frequently and the frequency of rainstorms has been high. Excessive rainfall has brought many secondary geological disasters, including landslides and mudslides. The typical landslide hazards in the area were mostly U-shaped, and the vegetation cover in the landslide was scarce. Therefore, the article selected landforms, precipitation, vegetation coverage as a factor of fractal research.

\subsection{Fractal characteristics of spatial distribution of landslides in Dachuan District}

The 395 landslide disaster points in Dachuan District were plotted on the administrative region map, and the topographic maps were then covered with square grids with side lengths of $\mathrm{r}=1,2,4,8$, and $16 \mathrm{~km}$ (Figure 1). Figure 1 showed the number of squares containing the landslide hazard point and drew the data into table 1 .

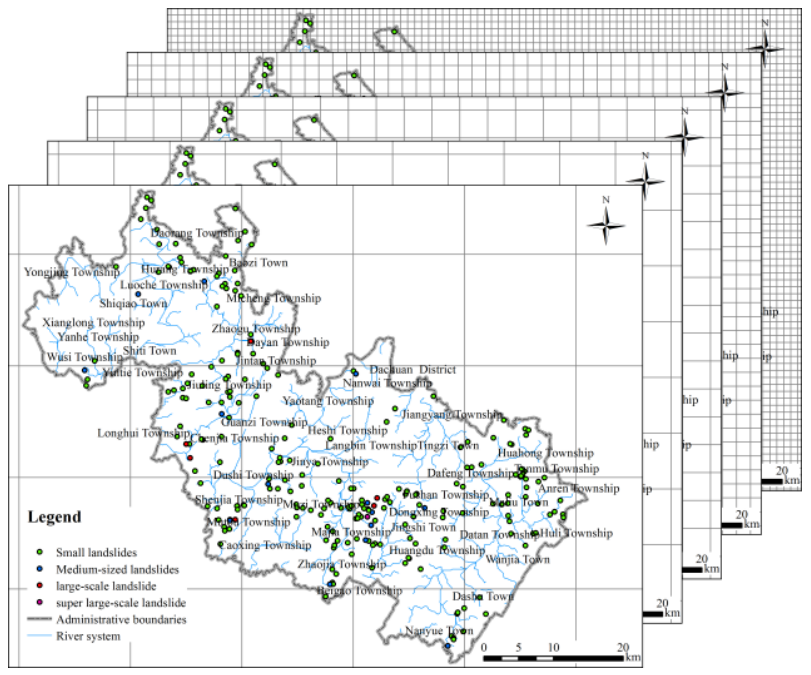

Figure 1. The Sketch map of spatial distribution of landslide in Dachuan District

\begin{tabular}{|l|c|}
\hline Grid length $(\mathrm{km})$ & Number of grids containing disaster points \\
\hline 1 & 207 \\
\hline 2 & 157 \\
\hline 4 & 90 \\
\hline 8 & 42 \\
\hline 16 & 17 \\
\hline
\end{tabular}

Table 1. The statistics of box dimension of spatial distribution of landslide in Dachuan District

We used the statistical data of Table 1 , with ri and $\mathrm{N}$ (ri) as horizontal and longitudinal coordinates, the point ri and $\mathrm{N}$ (ri) $(r=1,2,4,8,16)$ were plotted on a double logarithmic coordinate diagram. Then the least square method is used to fit the straight line, and the absolute value of the line slope is the fractal dimension of the spatial distribution of the landslides in the Dachuan area. Finally, the fitting line of landslide disaster point in Dachuan District was $y=-1.0119 x+5.9588$, and the correlation coefficient $\mathrm{R}^{2}=0.9564$. Landslide disaster point fitting diagram was shown in Figure 2.

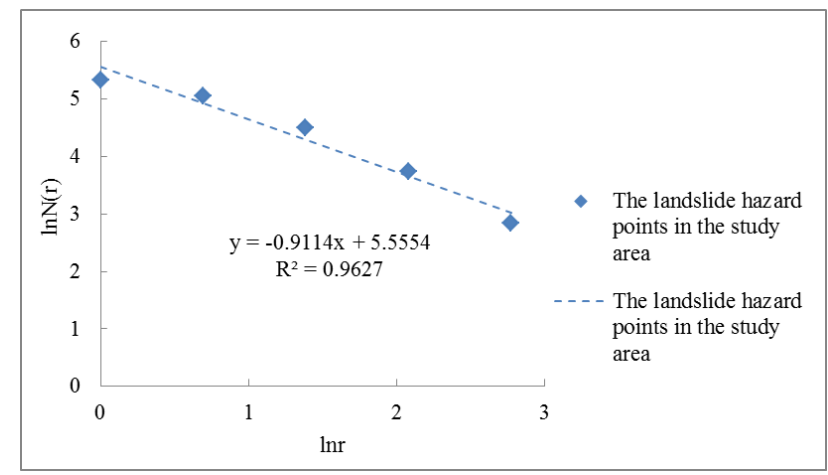

Figure 2. Fitting straight line of $\ln -\ln N(r)$ of landslide hazard points in Dachuan District

As shown in Figure 2, the fractal dimension value and the correlation coefficient were higher in the scope of the administrative division of the Dachuan District, and the fractal dimension correlation was strong. It was concluded that the spatial distribution of geological hazards in Dachuan District was complex and the autocorrelation was obvious.

\subsection{Fractal features of landslide disaster points distribution in different types of landforms}

Dachuan District is located in the parallel ridge zone of East Sichuan, which belongs to the landforms of "Fold denudation and erosion in low mountain and hilly valley of East Sichuan". The geomorphic features are completely controlled by the structure and lithology. The main types of geomorphology are low mountain, deep hill, middle hill and shallow hill. A single geomorphic type was divided into one area, and each geomorphologic interval (i) was divided into basic statistical units, and the number of grid numbers with disaster points $\mathrm{N}$ (r) was counted. The statistical data shown in Table 2 were obtained.

\begin{tabular}{|l|c|c|c|c|c|}
\hline Grid length(km) & 1 & 2 & 4 & 8 & 16 \\
\hline Low mountain & 49 & 37 & 24 & 15 & 8 \\
\hline Deep hill & 102 & 81 & 50 & 23 & 11 \\
\hline Middle hill & 36 & 30 & 20 & 11 & 5 \\
\hline Shallow hill & 21 & 18 & 11 & 6 & 3 \\
\hline
\end{tabular}

Table 2. Statistical results of space distribution box dimension of disaster points based on geomorphic types

Due to the fact that Pingba is less distributed in Dachuan District, it accounts for less than $1 \%$ of the entire area. The Pingba area has too few disaster spots and therefore does not participate in discussions. The ri and $\mathrm{N}$ (ri) values of the hilly and low-mountain partitions were plotted on the double logarithmic graph, and the least squares method was used to fit the straight line. The distribution curve of landslide hazard distribution points in the Dachuan area was obtained. As shown in Figure 3. 


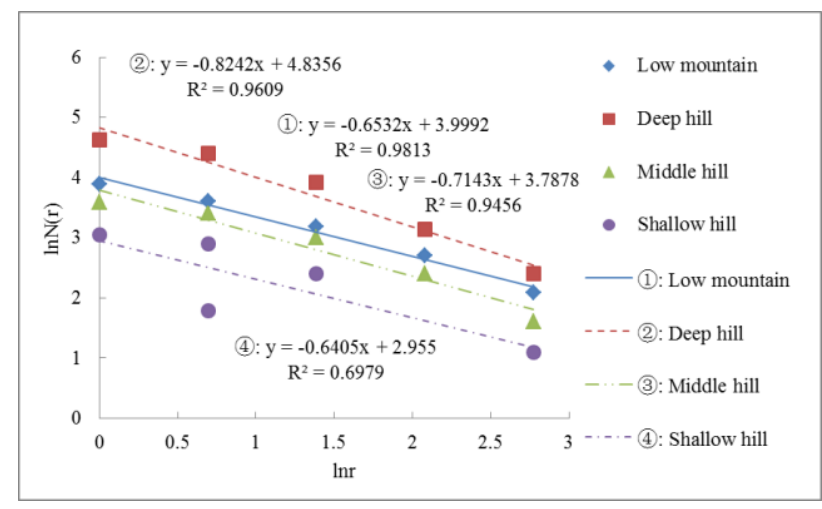

Figure 3. Fitting straight line of $\ln -\ln N(r)$ of landslide hazard points based on geomorphic types

The calculation results showed that the spatial distribution of landslide hazard points in various geomorphic units had high fractal dimension correlation and obvious linear relationship (correlation coefficient is greater than 0.69 , fractal dimension was between (0.7405-0.8242), and its fractal dimension was less than the fractal dimension of the spatial distribution of landslide hazard in the Sichuan Basin.

\subsection{Fractal characteristics of the distribution of landslides in the annual average rainfall area}

The rainfall equivalent map was generated based on the annual average precipitation in 2013 in Dachuan District. Each rainfall interval divided is the basic statistical unit. The equivalent maps are shown as $r=1,2,4,8$, and 16 on the administrative division map. The $\mathrm{km}$ is divided into a number of small square grids for the side length, and the number of grid points $\mathrm{N}(\mathrm{r})$ for the disaster points is counted, and the statistical data shown in Table 3 is obtained.

\begin{tabular}{|l|c|c|c|c|c|}
\hline Grid length $(\mathrm{km})$ & 1 & 2 & 4 & 8 & 16 \\
\hline$>1250 \mathrm{~mm}$ & 38 & 36 & 22 & 14 & 9 \\
\hline $1150-1250 \mathrm{~mm}$ & 84 & 59 & 35 & 17 & 8 \\
\hline $1050-1150 \mathrm{~mm}$ & 56 & 45 & 33 & 21 & 12 \\
\hline$<1050 \mathrm{~mm}$ & 31 & 21 & 15 & 9 & 6 \\
\hline
\end{tabular}

Table 3. Statistical results of the spatial distribution box dimension of disaster points zoned according to annual rainfall

According to the statistical data, the R (I) and N (RI) values of each rainfall area were labeled on the double logarithmic coordinate map. The least squares fitting method was used to fit the straight line, and the fitting curve of the distribution of landslide disaster points in the annual rainfall area of the Sichuan Basin was obtained, as shown in Figure 4.

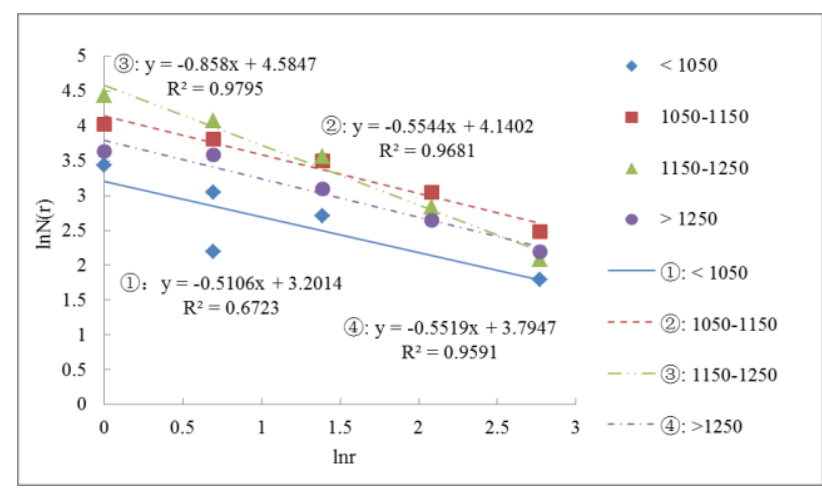

Figure 4. Fitting straight line of $\ln -\ln N(r)$ of landslide hazard points based on annual rainfall division

From the results of the box dimension method shown in Figure 4 , we can see that the fractal dimension of landslide disaster points in each precipitation area is between 0.51-0.85, showing a linear distribution with high correlation. The fractal dimension is still smaller than that of Dachuan District.

\subsection{Fractal characteristics of distribution of landslides in subarea of vegetation coverage}

After preprocessing the 2013 NDVI data in Dachuan District, the monthly data was synthesized into annual data according to MVC (maximum synthesis method). Inverting the vegetation coverage of Dachuan District according to the dichotomy of pixels:

$$
V F C=\frac{N D V I-N D V I_{\min }}{N D V I_{\max }-N D V I_{\min }}
$$

where $\quad V F C=$ Vegetation coverage

$N D V I_{\min }=$ The smallest NDVI value in the area

$N D V I_{\max }=$ The largest NDVI value in the area .

Each section of vegetation coverage divided into basic statistical units is divided into several small square grids with $\mathrm{r}$ $=1,2,4,8$, and $16 \mathrm{~km}$ as the side length of the coverage map. The number of grids $\mathrm{N}(\mathrm{r})$ gives the statistical data shown in Table 4.

\begin{tabular}{|l|c|c|c|c|c|}
\hline Grid length(km) & 1 & 2 & 4 & 8 & 16 \\
\hline$<30 \%$ & 3 & 3 & 3 & 3 & 3 \\
\hline $30 \%-60 \%$ & 188 & 143 & 84 & 41 & 17 \\
\hline$>60 \%$ & 20 & 19 & 15 & 14 & 10 \\
\hline
\end{tabular}

Table 4. Statistical results of space distribution box dimension of disaster points based on vegetation coverage

Because the area where the vegetation coverage is less than $30 \%$ is too small, the disaster points are too few to participate in this study. According to the statistical data, the r(i) and N(ri) values of each vegetation coverage area are marked on the double logarithmic graph, and the least squares method is used to fit the straight line to obtain the distribution of landslide disaster points in the vegetation coverage of Dachuan District. As shown in Figure 5. 


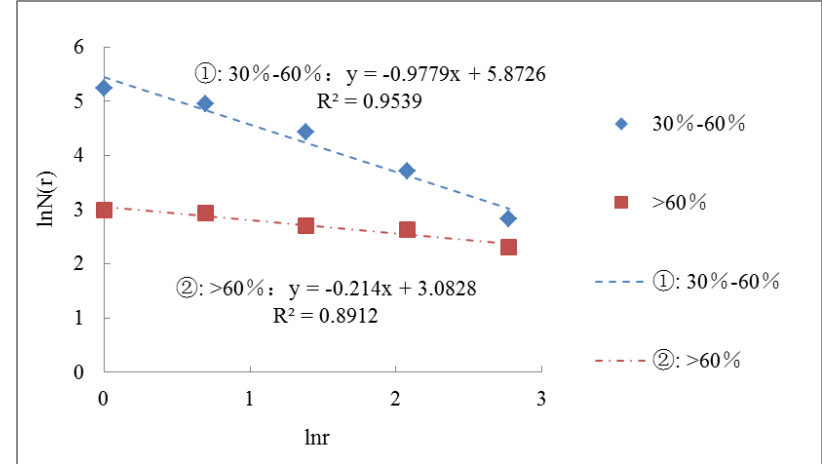

Figure 5. Fitting straight line of $\ln r-\ln N(r)$ of landslide hazard points based on based on vegetation coverage

From Figure 5, the box counting method was applied to determine the landslides. The results showed that when the vegetation coverage was $30 \%-60 \%$, the landslides had more linear distribution and strong correlation (0.9539). The fractal dimension is still smaller than that in the whole area of Dachuan District.

\subsection{Fractal Theory Guides Landslide Hazard Area Classification}

Fractal theory is used to characterize the intrinsic connection of a large number of seemingly irregular things, while the fractal dimension expresses the degree of intrinsic connection of things Therefore, based on the size of the fractal dimension (Table 5), the article has obtained the potential impact of landforms, rainfall, and vegetation on the distribution of disaster points (Figures 6,7, and 8). The analytic hierarchy process (AHP) was used to determine the weight of the 3 factors: the landform type was 0.633 , the annual rainfall was 0.261 , and the vegetation coverage was 0.106 . The potential hazard distribution map of the single impact factor was obtained from the potential hazard zoning of the landslides in the region of Sichuan Province (Figure 9).

\begin{tabular}{|l|c|c|c|}
\hline Level of factor & $\begin{array}{c}\text { Low danger } \\
\text { zone }\end{array}$ & $\begin{array}{c}\text { Middle } \\
\text { danger zone }\end{array}$ & $\begin{array}{c}\text { High } \\
\text { danger zone }\end{array}$ \\
\hline Annual rainfall $(\mathrm{mm})$ & $<1050$ & $>1250$ & $1050-1250$ \\
\hline Geomorphic type & Shallow hill & $\begin{array}{c}\text { Low } \\
\text { mountain }\end{array}$ & $\begin{array}{c}\text { Deep hill, } \\
\text { Middle hill }\end{array}$ \\
\hline $\begin{array}{l}\text { vegetation } \\
\text { coverage( } \%)\end{array}$ & $<30$ & $>60$ & $30-60$ \\
\hline
\end{tabular}

Table 5. Risk classification of potential landslides in Da Chuan District

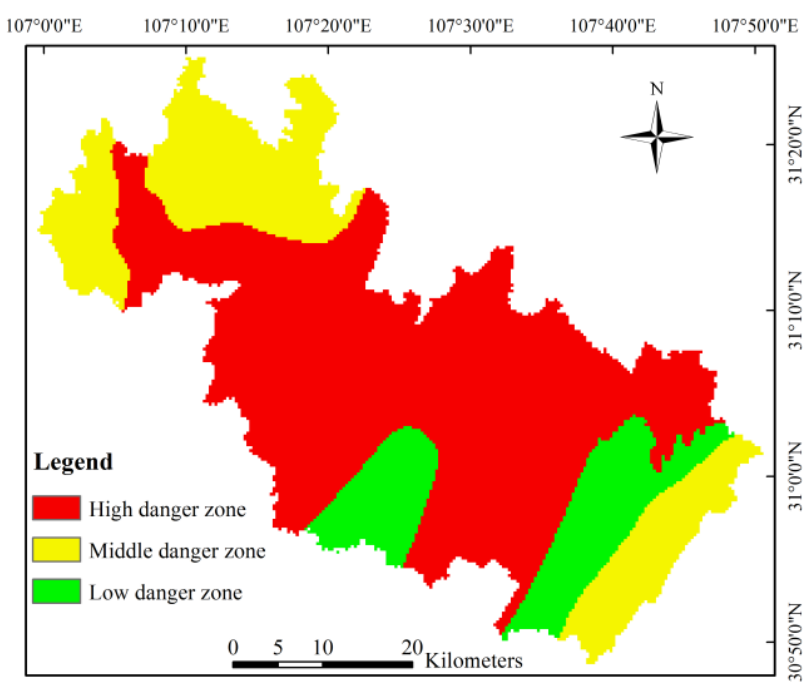

Figure 6. Potential hazard zone divided according to landforms

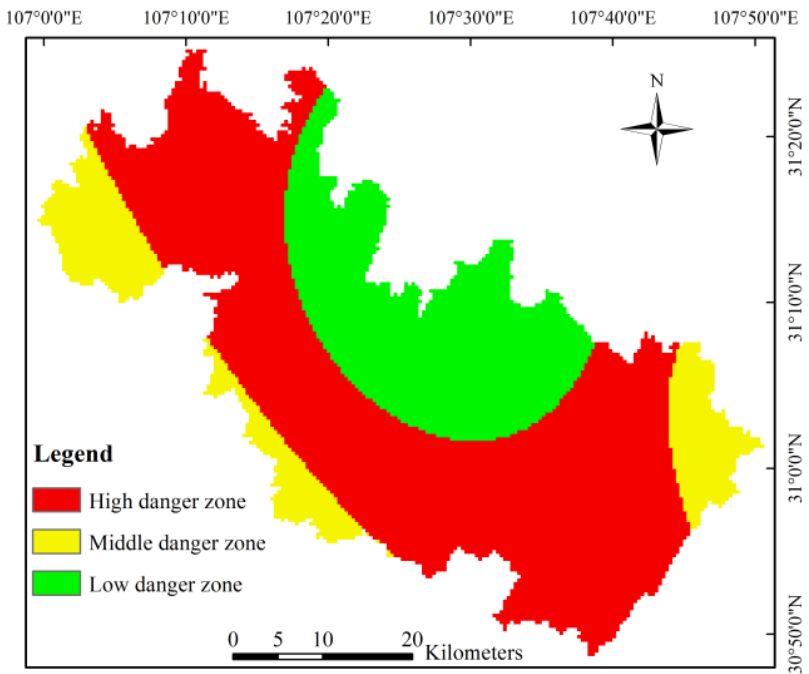

Figure 7. Potential hazard zone divided according to annual rainfall 


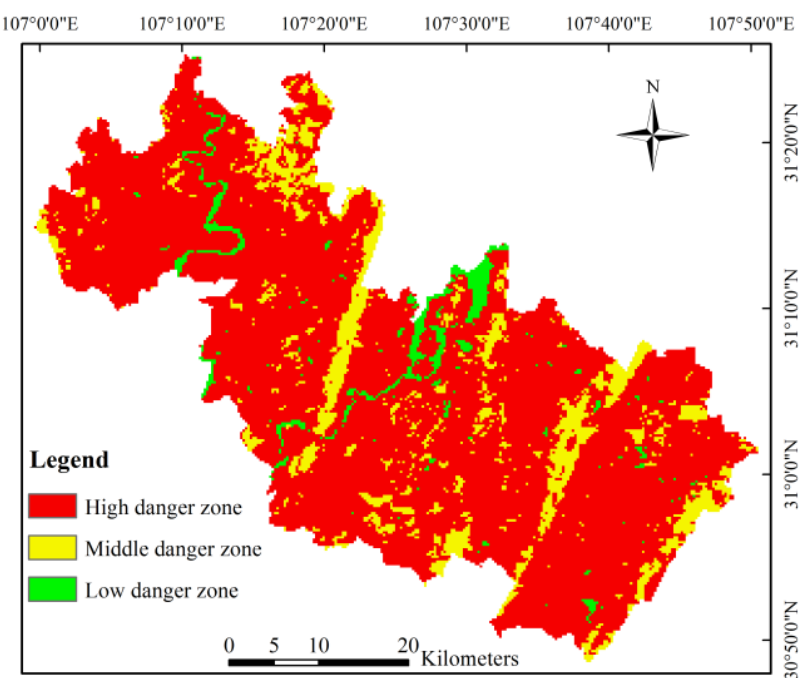

Figure 8. Potential hazard zone divided according to vegetation coverage

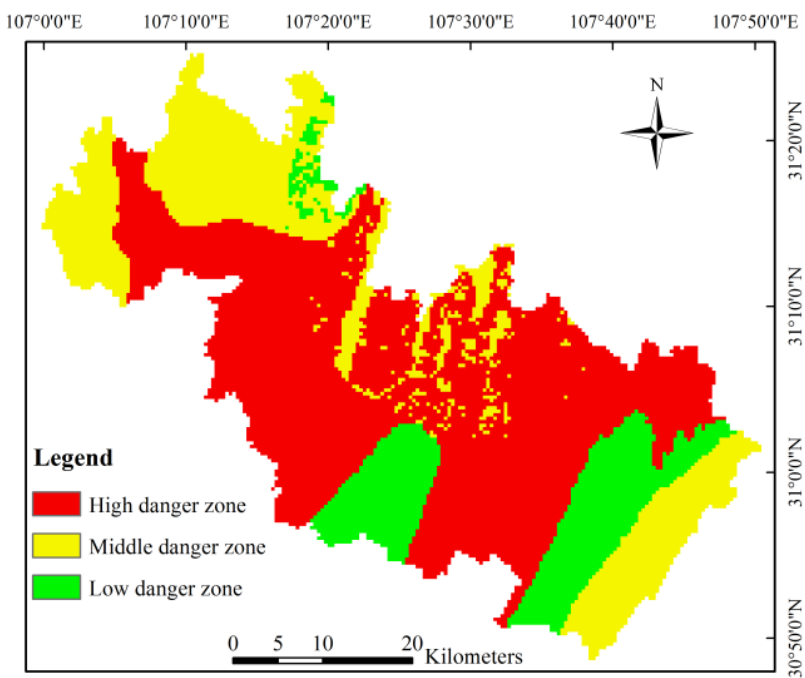

Figure 9. Potential hazard zoning in Dachuan District

From Figure 9 we can see that the potential danger areas in Dachuan District are divided into high danger zone, middle danger zone, and low danger zone. The high danger areas were mainly located in deep hills, middle hills, annual rainfall of $1050-1025 \mathrm{~mm}$, and vegetation coverage of $30 \%-60 \%$. The middle danger areas were mainly located in the low mountains, the average annual rainfall was more than $1025 \mathrm{~mm}$ and the vegetation coverage was more than $60 \%$; The low danger areas were mainly located in shallow hills, annual rainfall was less than $1050 \mathrm{~mm}$, and vegetation coverage was less than $30 \%$.

\section{CONCLUSION AND DISCUSSION}

This paper uses variable dimension fractal to study the distribution of landslide hazards in Dachuan District. The analysis results showed that the space of landslide disaster points had self-similarity and strong fractal correlation. Although the spatial distribution of landslide disaster points under the division of landform type, annual precipitation, and vegetation coverage had a good fractal correlation, Compared with Dachuan District-wide correlation, it was still weak.

According to the fractal dimension value, the geomorphic types are sorted by the size of the fractal dimension: deep hill > middle hill > low mountain > shallow hill (in descending order). The deep dune geomorphology areas, with a sea level elevation of 320-800 $\mathrm{m}$ and a relative height difference of $150-400 \mathrm{~m}$, are distribuetd in the axis and the two wings of the anticline in the middle mountains. The attitude of stratum of the west wing is gentle with the dip angle of 10-25 degrees, while the east wing is steepy with the dip angle of 20-47 degrees. Due to tectonic fractures, weathering fracture, and broken rock mass, deep hills are liable to form landslides. For middle mound geomorphic areas where the elevation is of $300-450 \mathrm{~m}$ and the relative height difference is $80-150 \mathrm{~m}$, the exposed strata in these areas are mainly mudstone, silty mudstone and sandstone, siltstone of the Suining Formation and Shaximiao Formation of the Jurassic. The stratiform axis shape is relatively gentle while the two wings are steep with the dip angle of $10^{\circ}-35^{\circ}$. Although middle hills feature the loose structure, there are fewer disasters. The elevation of the shallow hilly geomorphic area is $280-440 \mathrm{~m}$, the relative height difference between the hills and valleys is 50$70 \mathrm{~m}$. Wide valleys, gentle slopes, and small topographic relief in this area form the gentle attitude of stratum with the dip angle of $5^{\circ}-20^{\circ}$. Compared with the former two types, this area has better geological condition and less disaster in return. In Dachuan District, low mountains occupy the largest area, while there are also extremely steep slopes on either side, narrow vallies in the middle, and $\mathrm{V}$-shape gullies distributed, characterizing this region the undulate topography and minor landslides. Its elevation is $420-1000 \mathrm{~m}$ and relative height difference is $150-500 \mathrm{~m}$.

The fractal dimension obtained from the annual average rainfall partition can be placed in ascending order: $1150 \mathrm{~mm}-1250 \mathrm{~mm}$, $1050 \mathrm{~mm}-1150 \mathrm{~mm},>1250 \mathrm{~mm}$ and $<1050 \mathrm{~mm}$. Regions with the annual average precipitation of $1050 \mathrm{~mm}-1250 \mathrm{~mm}$ are mainly low mountains and most hilly areas which uasually suffer from the landslide disasters jointly caused by large precipitation, topographic features, and relatively weak lithology. Regions with the annual precipitation of $>1250 \mathrm{~mm}$ are the main part of the shallow hilly, flatland and hilly areas. Although the rainfall is relatively high, the geological conditions here are good at a low probalibity of disasters. Due to the rainfall and areas with the $<1050 \mathrm{~mm}$ precipitation are both small, the possibility of disaster is the lowest.

Among the fractal dimension values obtained by vegetation coverage, order by value size is in turn: $<30 \%, 30-60 \%,>60 \%$. There are more distribution and stronger correlation of landslides in the area whose vegetation coverage between $30 \%$ and $60 \%$. In areas with vegetation coverage greater than $60 \%$, the greater the vegetation coverage, the less the distribution of the landslide disaster points. Areas with less than 30\% vegetation coverage are too few, so it does not participate in the discussion.

Verifying the potential hazard zoning map of the potential landslides with 145 remaining disaster points, among them, there are 74 landslide hazard points in high risk area, accounting for $51.03 \%$ of the total. There are 59 landslides in the middle risk area, accounting for $40.69 \%$ of the total, and 12 in the low risk area, accounting for $8.28 \%$ of the total. The matching degree of the verifying result and the potential hazard 
zoning is high. Therefore, it can be more intuitively described the influence degree of the influence factors on the geological disaster points by using the fractal dimension to divide the geological hazard easily. It is able to get the major factors that affect the distribution of disasters, and divide the potential hazard zoning map to provide a theoretical basis for decisionmaking departments to take reasonable and effective governance methods.

\section{REFERENCES}

Du, L., 2017. Study on the temporal and spatial distribution and Influencing factors of landslide hazards in Wenzhou City based on GIS. Gansu Science and Technology, 33(7), pp. 24-28.

Yan, Y., and Yue, C. T., 2004. Discussion on the characteristics and countermeasures for the geological hazard in Sichuan Province. Chinese Journal of Geological Hazard \& Control, 15(z1), pp. 123-127.

Luo, X. L., 2014. On the problems in the management of the special funds for the prevention and control of geological disasters in Sichuan. Acta Geologica Sichuan, 34(3), pp. 477480 .

Zhang, C. Y., Meng, H., Zhang, R. L., and Li, Y. M., 2017. Risk assessment of regional unit geological hazards in China. Hydrogeology \& Engineering Geology, 44(2), pp. 160-166.

Han, X., and Zhang, N., 2017. Analysis of coupling coordination degree of urbanization and geological disaster based on TOPSIS. Hydrogeology \& Engineering Geology, 44(2), pp. 167-171.

Zhang, Z. J., and Zhuang, Y. C., 2017. Geological hazard remote sensing based on GF-1 data - Taking Datong County of Qinghai Province as an example. Science Technology and Engineering, 17(18), pp. 9-17.

Zieher, T., Perzl, F., Rössel, M., Rutzinger, M., Meißl, G., Markart, G., and Geitner, C., 2016. A multi-annual landslide inventory for the assessment of shallow landslide susceptibility - Two test cases in Vorarlberg, Austria. Geomorphology, 259, pp. $40-54$

Caccavale, M., Matano, F., and Sacchi, M., 2017. An integrated approach to earthquake-induced landslide hazard zoning based on probabilistic seismic scenario for Phlegrean Islands (Ischia, Procida and Vivara), Italy. Geomorphology, 295.

Schilirò, L., Montrasio, L., and Mugnozza, G. S., 2016. Prediction of shallow landslide occurrence: Validation of a physically-based approach through a real case study. Science of the Total Environment, s 569-570, pp. 134-144.

Luo, X. Y., Liu, Y. Y., Li, F., and Zhang, J., 2017. Study on the system of watershed space division. Yangtze River, 48(6), pp. 17.

Office of the People's Government of Dachuan District in Dazhou City, 2017. Dachuan Introduction, Open Source Geospatial Foundation http://www.dachuan.gov.cn/govopen/ show. cdcb?id=416273 (22 November 2017).

Burrough, P. A., 1981. Fractal dimensions of landscapes and other environmental data. Nature, 294(5838), pp. 240-242.
Zhang, J. R., Wang, J. M., Zhu, Y. C., Li, B., and Wang, P., 2017. Research progress of fractal theory in the application of Soil Science. Chinese Journal of Soil Science, (1), pp. 221-228.

Yang, L., Zhu, Y. S., and Wang, K. F., 2017. Study on the gradation and variation of asphalt mixture by fractal geometry theory. Engineering and Construction, 31(1), pp. 15-19.

Ding, J. H., 2012. Study on gas geological law and regional prediction index of two 1 coal seam in Pei Gou mine. Henan Polytechnic University.

Wen, H., 2013. Study on the distribution and fractal characteristics of landslides in Nanxi District of Sichuan Province. Xi`an University Of Science And Technology. 